\title{
Educational Technology: Hop Step Jump through the Learning Communities
}

\author{
Piet Kommers \\ Faculty of the Behavioral Sciences, University of Twente \\ Enschede; the Netherlands \\ Kommers@edte.utwente.nl
}

\begin{abstract}
Educational Technology in the last two decades has conquered the position of intermediate between the autonomous fields of pedagogy and technology. This panel contribution aims at outlining the new Ph.D. school in Joensuu. What should we expect from the candidates before they start? What are the unique selling points of the ET Ph.D. School in Joensuu?
\end{abstract}

\section{Introduction}

Like in many disciplines, there is a continuous need to refresh paradigms. Early ambassadors of the term (ET) Educational Technology were Syracuse University and Twente University in the late 70ties. It is not that important to understand why they felt this need so early; more important is to see if it still will be a vital marriage the coming years. Seen the title of this panel I think that we need to look at its next generation. The most intriguing at the time is "Autonomous WWW-based Learning Communities." Let's resume the "Hop Step ee Jump" metaphor.

- Pedagogy is the hop (Sisyphus job as we theorize on one of the most close and personal human expressions of how to acquaint your offspring with the world).

- Technology is the step; without semiconductor impulse after space expeditions, we still would be quite happy with glossy, but still static pages on our desks.

- WWW-based Learning Communities is the "Jump forward". Its claim is that learning for obtaining a certificate is suboptimal. It comes close to the provocative "De-schooling Society" and "The Pedagogy of the Oppressed" by Illich and Freire resp. [1] and [2].

The impact of mobile phones with built-in PDAs on learning in average social life, gaming and work cannot be overestimated. See "Handheld Education" [3].

\section{Education and Technology, a Continuous Love Affair?}

Without migrating the school and certificate into a real asset (a flexible, life-long joy for willingness to change our mind for a more human society) its contribution to real education and training remains shallow and cosmetic. In order to continue this allegory: it remains urgent the coming years to make "hop" and "step" understand each other. Father and mother fell in love; maybe because they did not understand each other yet. Maybe that's the power of gender. How can we merry a member of another tribe, without a double difference? [4] Typical phenomena all these years of ET conferences are that pedagogues think that technologists will fix the job, and vice versa. However as soon as one makes a courageous step forward, the other gets nervous: "Is this all?"

The real progress is not so much in the meticulous change of both parents. Much more can be expected from their children who did never participate in the endless disputes on phenomenology/ behaviorism/ cognitivism/ constructivism, similar to those of us who struggled in the stages of procedural/ declarative/ functional, object-/aspect oriented etc. The tribes will only pay-off after they reconciled without knowing each other. How will the baby look like?

\section{Expertise as a Social Compromise}

It seems that de-institutionalized learning is the baby; Self-organizing networks of persons who feel a need to understand important things in life better. Is it the end of hegemony of experts? No, in contrary; only the expert of today is not necessarily the expert in the problems of to-morrow. Like monarchs nowadays know that inheritance is only a futile factor in wisdom; we continuously become aware that expertise manifests between rather than in persons. Similar will be the mentality in learning communities: Post modernism accepts truth as just the outcome of a social battle. Rather than appointing teachers who won the 
battle and let them propagate to the receptive younger generation, it will be the youngsters themselves who join the battle and create new views that would never be accepted by the authors of yesterday. ET will take part in the fundamental debate on the balance between transferring the known versus let students learn by exploring the unknown.

\section{Ph.D. School in the Field of Educational Technology}

Now; what does this tell us about raising a new Ph.D. School on Educational Technology? I think first of all, Ph.D. means qualifying yourself as autonomous responsible and integer researcher who can contribute to actual research agendas and be able to do methodologically fair experimentation. I fully agree on that with Mike Joy. Beyond that I think it has been demonstrated already for a long time that educational researchers need to be able to concretize their ideas in prototypes and define and implement appropriate practical conditions in order to test the validity of their ideas. It's hard to divide the ideation and the pragmatic along various persons, as the concretization is in fact much more decisive than we want to believe. The analogy with architect versus the bricklayer is not valid yet. In building we have a rather saturated set of rules between "what" and "how" to build. Interactive programs still exceed the level of didactic imagination. The typical fact is that didactic innovation has all the time rested upon valuable pragmatic opportunities, like the book print, the interactive video and nowadays the www-sensitive mobile phone/PDA.

\section{Boys and Girls be Ambitious}

As contribution to this panel I cordially recommend the new Ph.D. candidates to theorize and experiment on actual technological novelties in an unscrupulous way. Seymour Papert (being a student of Jean Piaget) showed a remarkable creativity to transplant the understanding of how the child's mind differs essentially from the adult, into LOGO as a seed for becoming aware how concepts develop rather than 'transfer'. Indeed I am convinced that a Ph.D. is not "following a course". It is undertaken a study field with unexpected outcomes. Currently being in Sapporo (Japan) I quote Dr. William S. Clark saying to his students at the end of the $19^{\text {th }}$ century: "Boys be Ambitious"; [5].

\section{Conclusion}

As final conclusion: The new Ph.D. school is not a goal in itself. Even acquiring the title is not a valid goal in itself. Its goal is to facilitate progress in optimizing and understanding learning procedures, in this case especially when media play a crucial role in it. Unique selling points of the Joensuu ET Ph.D. school:

1. Addressing vital questions for education and training rather than intellectually interesting ones. Examples are learning and its impact on economy, emancipation, peace and the quality of life.

2. Widening the horizon from national and western towards learning needs in the $3^{\text {rd }}$ world countries with a considerable lower infrastructure.

3. Anticipating to new learning scenarios, including those that will develop as (virtual) learning communities.

4. Being inspired by newly appearing media and underlying technologies. Attempting to conceptualize, implement and empirically assess its effects and impact.

5. Candidates should demonstrate a high intrinsic motivation and engagement in respect to the vividness of a proposed research question, methodology, test setting and the willingness to finally apply the research outcomes in the aimed target situations.

\section{References}

[1] Illich, Ivan (1973a) Deschooling Society, Harmondsworth: Penguin. 116 pages. (published by Harper and Row 1971.

[2] P. Freire. 1970. The Pedagogy of the Oppressed. New York: Herder and Herder.

[3] Handheld Education http://handheldeducation.com/gettingstarted.html

[4] Bennett, D., C. Brunner, and M. Honey. 1996. Gender and Technology: Designing for Diversity. Paper presented at the Regional Equity Forum on Math, Science, and Technology Education.

[5] http://www.clark.ed.jp/english/philosophy/ 